\title{
COMMENTARY
}

\section{Impact estimates of nosocomial bloodstream infection: looking from a different angle}

\author{
Dirk Vogelaers', Marie-Laurence Lambert ${ }^{2}$ and Stijn Blot ${ }^{* *}$ \\ See related research by Prowle et al., http://ccforum.com/content/15/2/R100
}

\begin{abstract}
Mortality associated with nosocomial bloodstream infection is multifactorial. Source of infection, etiology, age, underlying disease, acute illness, and appropriateness of antimicrobial therapy all contribute to the final outcome. As such, estimates of mortality attributable to bloodstream infection may differ largely according to the presence or absence of risk factors in distinct patient populations. The adverse effect of nosocomial bloodstream infection for the individual patient is substantial, with about a doubling of the risk of death. Yet, in settings with a high standard of care in terms of infection prevention and control, the occurrence rate of bloodstream infection is relatively low and therefore its impact on overall ICU mortality rather limited. As a consequence, untargeted interventional studies focused on infection prevention should use occurrence rate of infection rather than mortality as outcome variable.
\end{abstract}

In a previous issue of Critical Care, Prowle and colleagues describe the results of a cohort study in which incidence and attributable mortality of bloodstream infection (BSI) were investigated in university-affiliated hospitals [1]. The cohort included 6,339 patients with an ICU stay $>72$ hours, of which 330 developed an ICU-acquired BSI. Mortality associated with BSI was $41.2 \%$ and thereby substantially higher compared to patients without BSI (22.5\%). After adjustment for confounding covariates, BSI remained an independent risk factor for death (hazard ratio 2.9, 95\% confidence interval 2.4 to 3.5). The study by Prowle and colleagues, however, goes beyond impact estimates for patients who are affected by this

*Correspondence: stijn.blot@ugent.be

'General Internal Medicine and Infectious Diseases, Ghent University Hospital,

De Pintelaan 185, 9000 Ghent, Belgium

Full list of author information is available at the end of the article infectious complication. The investigators linked the attributable risk of death to the incidence of BSI, which was approximately $5 \%$ in this cohort. The authors state that, taking into account the low incidence, the overall impact of nosocomial BSI on the total study population was small as it only caused a decrease in overall survival of approximately $1 \%$. As such, the study by Prowle and colleagues is remarkable as it evaluates the deleterious impact of BSI in bacteremic patients and in the overall ICU cohort.

For what concerns the impact for patients with BSI, the study results concur with those of other investigators who found dramatic excess mortality rates, albeit that some researchers reported attributable mortality rates of non-significant proportions [2-4]. Within certain confidence limits, all of these estimates might match reality as clinical outcomes are multifactorial and variable depending on the specific characteristics of the study cohort [5].

More unusual and controversial is to express the excess mortality of BSI for the overall population. Even in a situation where substantial excess mortality was noted in the bacteremic cohort, the deleterious impact appears to be of minor importance when using the overall cohort as denominator. This finding has several consequences that must be addressed. As the authors themselves point out, survival benefit of untargeted interventions to prevent BSI is hardly feasible, and any claims of improved survival from interventions to reduce BSI must therefore be interpreted cautiously. We fully concur with these statements. As BSIs hardly affect overall mortality, huge trials in prevention are necessary to demonstrate benefits in mortality. One might question whether mortality is, per se, the best outcome variable. As already mentioned, mortality always is a product of many components. Also, plenty of studies, including the present one by Prowle and colleagues, show that BSIs do result in a significant excess risk of death. It seems appropriate, therefore, that infection rate in itself, and not mortality, is the best suited outcome variable. The data provided by Prowle and colleagues show that, for interventional studies in infection prevention, study power should be calculated as a function of a predefined reduction in infection rate, 
rather than decreased mortality. Vice versa, study results of such trials indicating a reduced infection risk but without difference in mortality should not be taken as a justification of non-adherence, on the condition that associated costs are not excessive.

Although mathematically correct, the approach of considering the impact of BSI on population level calls for some vigilance. By diluting the effect of infection there exists a risk of downplaying the importance of a severe complication. Even though Prowle and colleagues clearly do not enlighten their study results with this purpose, the present data could be used as an argument to minimize the problem and a reason not to invest in infection prevention. In this way, the consequences of many other severe complications can be downgraded to apparently negligible proportions. For example, acute kidney injury with need for renal replacement therapy is well-known to be one of the strongest risk factors for death in patients with severe burn injury. Acute kidney injury occurs in approximately $3 \%$ of severely burned patients and is associated with a mortality rate of about $30 \%$ [6]. The average baseline mortality in burn patients has been estimated to be 5\% [7]. Based on these figures, it can be calculated that acute kidney injury increases mortality by only $0.9 \%$ (from $4.85 \%$ to $5.75 \%$ ). This example illustrates how the impact of complications can be diminished by alterations in denominator.

The study by Prowle and colleagues demonstrates that assessing the impact of BSI should preferably be performed on the patient group affected as many other ICU patients have only a very low risk profile for the acquisition of nosocomial BSI. Diluting the impact of infection to the overall population, however, illustrates that infection prevention studies should use infection rates as endpoints, as proving substantial benefits in survival does not seem to be achievable.
Abbreviations

BSI, bloodstream infection.

\section{Competing interests}

The authors declare that they have no competing interests.

\section{Author details}

'General Internal Medicine and Infectious Diseases, Ghent University Hospital, De Pintelaan 185, 9000 Ghent, Belgium. ${ }^{2}$ Public Health and Surveillance Department, Scientific Institute for Public Health, J. Wytsmanstraat 14, 1050 Brussels, Belgium.

Published: 30 June 2011

\section{References}

1. Prowle JR, Echeverri JE, Ligabo EV, Sherry N, Taori GC, Crozier TM, Hart GK, Korman TM, Mayall BC, Johnson PD, Bellomo R: Acquired bloodstream infection in the intensive care unit: incidence and attributable mortality. Crit Care 2011, 15:R100

2. Garrouste-Orgeas M, Timsit JF, Tafflet M, Misset B, Zahar JR, Soufir L, Lazard T, Jamali S, Mourvillier B, Cohen Y, De Lassence A, Azoulay E, Cheval C, Descorps-Declere A, Adrie C, Costa de Beauregard MA, Carlet J; OUTCOMEREA Study Group: Excess risk of death from intensive care unitacquired nosocomial bloodstream infections: a reappraisal. Clin Infect Dis 2006, 42:1118-1126.

3. Blot S, Vandewoude K, Hoste E, J DW, Kint K, Rosiers F, DV, Colardyn F: Absence of excess mortality in critically ill patients with nosocomial Escherichia coli bacteremia. Infect Control Hosp Epidemiol 2003, 24:912-915.

4. Lambert ML, Suetens C, Savey A, Palomar M, Hiesmayr M, Morales I, Agodi A Frank U, Mertens K, Schumacher M, Wolkewitz M: Clinical outcomes of health-care-associated infections and antimicrobial resistance in patients admitted to European intensive-care units: a cohort study. Lancet Infect Dis 2010, 11:30-38

5. Blot S: Limiting the attributable mortality of nosocomial infection and multidrug resistance in intensive care units. Clin Microbiol Infect 2008, 14:5-13

6. Brusselaers N, Monstrey S, Colpaert K, Decruyenaere J, Blot SI, Hoste EA: Outcome of acute kidney injury in severe burns: a systematic review and meta-analysis. Intensive Care Med 2010, 36:915-925.

7. Belgian Outcome in Burn Injury Study Group: Development and validation of a model for prediction of mortality in patients with acute burn injury. BrJ Surg 2009, 96:111-117.

doi:10.1186/cc10271

Cite this article as: Vogelaers $D$, et al:. Impact estimates of nosocomial bloodstream infection: looking from a different angle. Critical Care 2011, 15:169. 